\title{
Geographic inequalities in pediatric emergency department visits in Ontario and Alberta: a multilevel analysis of $\mathbf{2 . 5}$ million visits
}

Piotr Wilk ( $\sim$ pwilk3@uwo.ca )

Western University

Alana Maltby

Western University

Tammy Lau

Western University

Anna C Gunz

Western University

Alvaro Osornio-Vargas

University of Alberta

Shelby S Yamamoto

University of Alberta

Shehzad Ali

Western University

Éric Lavigne

Health Canada

\section{Research Article}

Keywords: children, inequalities, urban, emergency department, geographic variation

Posted Date: March 7th, 2022

DOI: https://doi.org/10.21203/rs.3.rs-1386932/v1

License: (1) This work is licensed under a Creative Commons Attribution 4.0 International License.

Read Full License 


\section{Abstract}

Background: Research on intra- and inter-regional variations in emergency department (ED) visits among children can provide a better understanding of the patterns of ED utilization and further insight into how contextual features of the urban environment may be associated with these health events. To assess intraurban and inter-urban variation in pediatric emergency department (PED) visits in census metropolitan areas (CMAs) in Ontario and Alberta, Canada and explore if contextual factors related to material and social deprivation, proximity to healthcare facilities, and supply to family physicians explain this variation.

Methods: A retrospective, population-based analysis of data on PED visits recorded between April 1, 2015 and March 31, 2017 was conducted. Random intercept multilevel regression models were constructed to quantify the intra- (between forward sortation areas [FSAs]) and inter- (between CMAs) variations in the rates of PED visits.

Results: In total, 2,537,442 PED visits were included in the study. The overall crude FSA-level rate of PED visits was 415.38 per 1,000 children population. Across both provinces' CMAs, the crude rate of PED visits was highest in Thunder Bay, Ontario (771.65) and lowest in Windsor, Ontario (237.19). There was evidence of statistically significant and substantial intra- and inter-urban variation in the rates of PED visits. More socially deprived FSAs, FSAs with lower proximity to healthcare facilities, and CMAs with a higher rate of family physicians per 1,000 children population had higher rates of PED visits.

Conclusions: The variation in rates of PED visits across CMAs and FSAs cannot fully be accounted for by age and sex distributions, material and social deprivation, proximity to healthcare facilities, or supply of family physicians. There is a need to explore additional contextual factors to better understand why some metropolitan areas have higher rates of PED visits.

\section{Introduction}

According to more recent data from the Canadian Institute for Health Information's (CIHI) National Ambulatory Care Reporting System (NACRS), 21\% of ED visits in 2019-2020 occurred among those aged 0 to 19 years in Canada, with 38\% of these visits among children 0 to 4 years old [1]. The number of pediatric emergency department (PED) visits in Canada have been increasing [2-4], contributing to healthcare concerns related to ED overcrowding and disruptions to patient flow and care [4]. For instance, in a retrospective cohort study of visits to eight PEDs in four provinces (British Columbia, Alberta, Manitoba, and Ontario), the volume of PED visits increased annually between 2010 and 2014 [3]. In a PED in British Columbia, the volume of visits increased 30\% from 2002 to 2011.

With approximately $70 \%$ of Canadians currently living in census metropolitan areas (CMAs) [5], it is important to understand the determinants of variations in PED visits within (intra-CMA variation) and across (inter-CMA variation) these metropolitan areas [6-8]. These intra- and inter-urban variations may arise from contextual factors such as differential distribution of primary healthcare physicians within and across urban centers $[9,10]$, or proximity to healthcare facilities $[11,12]$. Previous research has indicated 
that greater primary care provider supply is associated with fewer non-urgent ED visits among children [13], and proximity to healthcare facilities has also been found to play an important role in the use of EDs [14]. Additionally, some research has highlighted the impact of area-level deprivation on health services utilization as children who live in deprived areas tend to have worse health outcomes than children living in more advantaged areas $[6,15]$. With increasing PED visits in Canada, additional research on intra- and inter-regional variations in ED visits among children can provide a better understanding of the patterns of PED utilization and further insight into how contextual features of the urban environment may be associated with these health events.

Currently, there is limited knowledge about geographic inequalities in PED visits in Canada's urban areas and the contribution of contextual factors to these inequalities, with most studies focusing on intra-urban variation in PED visits for respiratory conditions [6-8]. Therefore, this study aimed to quantify the magnitude of intra-metropolitan and inter-metropolitan variation in PED visits in large urban centers in Ontario and Alberta, Canada and assess if contextual factors related to material and social deprivation, proximity to healthcare facilities, and supply of family physicians can account for this variation.

\section{Methods}

\section{Study Design and Setting}

A retrospective, population-based analysis of secondary data on ED visits among children ( $<18$ years old) recorded between April 1, 2015 and March 31, 2017 in the CIHI's NACRS was conducted for children residing in provinces of Alberta and Ontario, Canada. Specifically, we selected PED visits recorded from 2015/2016 and 2016/2017 fiscal years to align them with the 2016 Census of Canada. The scope of this study was restricted to CMAs in Alberta and Ontario (19 in total) because only these two provinces had complete ED coverage for all years in the study period [16]. Ontario and Alberta are the largest and fourthlargest provinces in Canada with a population size in 2016 of 13,448,494 and 4,067,175, respectively [17]. Ethical approval was not required as this study used anonymous and confidential secondary data from $\mathrm{ClHI}$. Patient consent was gathered at the time of data collection. All methods were performed in accordance with the relevant guidelines and regulations.

\section{Study Population}

After pooling the NACRS datasets together for the two fiscal years, all unscheduled ED visits recorded among patients under the age of 18 residing in CMAs in Ontario and Alberta were included. Duplicate ED records and scheduled ED visits (i.e., when the ED visit date and time was fixed and the appointment was recorded in a scheduling system) were excluded from the analysis, as day surgeries or clinic visits may occur in EDs when organized clinic or day surgery areas are unavailable [18].

\section{Data Source}

The NACRS is a population-based health administrative database containing administrative, clinical, and demographic data on emergency and ambulatory care events, which includes ED visits, day surgeries, and 
outpatient clinics visits [16].

CMAs are geographic areas that are formed by one or more adjacent municipalities centered around a major urban core. A CMA must have a total population of at least 100,000 , and at least 50,000 of this population must live in the urban core [19]. To assess intra-metropolitan variation in PED visits, the Forward Sortation Areas (FSA) from the patients' residential address was used. FSAs are geographic areas defined by the first three characters of the Canadian postal code and were developed by the Canada Post Corporation to facilitate the mail delivery [20]. To establish correspondence between FSAs and CMAs, we used Statistics Canada's Postal Code Conversion File Plus (PCCF+) [21]. As FSAs do not perfectly correspond with Statistics Canada's census geographic boundaries, a single FSA may be matched with more than one CMA. To account for this, the PCCF+ uses a population-weighted allocation matching process [21].

\section{Measurements}

Outcome. The outcome of this study was the crude rate of PED visits in each FSA. This rate was calculated by dividing the total number of unscheduled PED visits observed among children residing in each FSA by the FSA-level population under the age of 18 years (derived from the 2016 Census of Canada). The rate was expressed as per 1,000 children population.

Contextual predictors. The material and social deprivation indices originally developed by Pampalon et al from census data were included as measures of FSA-level socioeconomic conditions to assess social inequalities. The indices used in our study were derived from the 2016 census data for the population aged 15 years and older [22, 23]. The material deprivation index is based on the proportion of people without a high school diploma, the employment/population ratio, and average personal income. The social deprivation index is derived from information on the proportion of people living alone, proportion of separated, divorced, or widowed people, and proportion of single-parent families. Statistics Canada's neighborhood proximity measures were also used to assess the proportion of dissemination blocks in each FSA that have at least one healthcare facility (i.e., physician offices, dentist offices, other health practitioner offices, community health centres, and hospitals) located in its boundaries [24, 25]. Finally, to measure the overall supply of family physicians in each CMA, we used data from the Canadian Medical Association on the total number of family physicians providing services in each CMA [26]. These counts were converted to rates of family physicians per 1,000 population.

Confounders. Differences in the distribution of specific demographic characteristics across FSAs may inflate the magnitude of geographic variation in PED visits. To control for some of these compositional effects, we included the following FSA-level factors: the proportion of children in each FSA that was between ages $0-4,5-9,10-14,15-17$ years and the proportion of children in each FSA that were female at the time of 2016 census.

\section{Statistical Analysis}


To describe the age, sex, and geographic distribution of the PED visits included in our analysis, we produced descriptive statistics (i.e., frequencies and proportions). We also computed means, standard deviations (SD), minimum and maximum values, and interquartile ranges for the outcome variable and the contextual predictors. To quantify the intra- (between CMA specific FSAs) and inter- (between CMAs) variations in the rates of PED, three random intercept multilevel regression models were constructed. First, a variance component model (Model 1) with only the outcome variable (FSA-level rate of PED visits) was constructed to estimate the overall magnitude of variation in the rates of PED visits and partition this variance into FSA- and CMA-level variances. Second, an adjusted model (Model 2) was constructed to control for compositional effects related to age and sex distribution. Finally, we ran a multilevel model in which we tested our hypotheses that FSA-level material deprivation, social deprivation, proximity to healthcare facilities, as well as supply of family physicians in each CMA can account for the observed variation in the rates of PED visits (Model 3). All statistical analyses were conducted using SAS 9.4 (SAS Institute Inc., Cary, NC, USA).

\section{Results}

\section{Descriptive Statistics}

Between April 1, 2015 and March 31, 2017, there were a total of 3,352,973 unscheduled PED visits made by children living in Alberta and Ontario. After selecting PED visits made by children residing in one of the 19 CMAs and removing visits from invalid (2,222 visits) and non-residential FSAs occupied by commercial entities (1,558 visits), there were 2,537,442 visits across 520 FSAs (103 FSAs in Alberta and 417 FSAs in Ontario) included in our analysis.

The univariate descriptive statistics of the PED visits are presented in Table 1. There were 1,280,180 PED visits in 2015/2016 and 1,259,262 visits in 2016/2017 fiscal years; overall, $72.42 \%$ of the PED visits were from Ontario and $27.58 \%$ from Alberta. The average age (years) was 7.17 (SD = 5.66), with the highest proportion of the PED visits made by children ages less than one (10.84\%). The sex distribution of PED visits was similar for males (52.94\%) and females (47.06\%). As indicated in Table 2, the mean crude FSAlevel rate of PED visits decreased from 418.03 per 1,000 children population in 2015/2016 to 412.73 in 2016/2017. The lowest rate was 143.57 while the highest rate was 1,131.52 per 1,000 children population. Across both provinces' CMAs, the crude rate of PED visits was highest in Thunder Bay, Ontario (771.65) and lowest in Windsor, Ontario (237.19). 
Table 1

- Descriptive statistics for pediatric emergency department visits

\begin{tabular}{|c|c|c|}
\hline Individual-Level Factors & Frequency $(\mathrm{N})$ & Percent (\%) \\
\hline \multicolumn{3}{|l|}{ Fiscal year } \\
\hline $2015 / 2016$ & $1,280,180$ & 50.45 \\
\hline $2016 / 2017$ & $1,257,262$ & 49.55 \\
\hline \multicolumn{3}{|l|}{ Age } \\
\hline 0 & 274,946 & 10.84 \\
\hline 1 & 275,140 & 10.84 \\
\hline 2 & 201,261 & 7.93 \\
\hline 3 & 163,412 & 6.44 \\
\hline 4 & 159,416 & 6.28 \\
\hline 5 & 136,102 & 5.36 \\
\hline 6 & 114,953 & 4.53 \\
\hline 7 & 103,761 & 4.09 \\
\hline 8 & 98,409 & 3.88 \\
\hline 9 & 96,324 & 3.80 \\
\hline 10 & 96,360 & 3.80 \\
\hline 11 & 96,786 & 3.81 \\
\hline 12 & 99,625 & 3.93 \\
\hline 13 & 104,973 & 4.14 \\
\hline 14 & 111,910 & 4.41 \\
\hline 15 & 122,286 & 4.82 \\
\hline 16 & 133,411 & 5.26 \\
\hline 17 & 148,367 & 5.85 \\
\hline \multicolumn{3}{|l|}{ Sex } \\
\hline Female & $1,194,101$ & 47.06 \\
\hline Male & $1,343,199$ & 52.94 \\
\hline Other & 142 & 0.00 \\
\hline
\end{tabular}




\begin{tabular}{|lll|}
\hline Individual-Level Factors & Frequency (N) & Percent (\%) \\
\hline Province of residence & & \\
\hline Ontario & $1,837,555$ & 72.42 \\
\hline Alberta & 699,887 & 27.58 \\
\hline
\end{tabular}

Table 2

- Descriptive statistics for rates of pediatric emergency department visits and contextual predictors

\begin{tabular}{|llllll|}
\hline FSA-Level Predictors & Mean & Std Dev & Minimum & Maximum & IQR \\
\hline PED visit rate - 2015/2016 & 418.03 & 165.66 & 66.67 & $1,166.34$ & 161.40 \\
\hline PED visit rate - 2016/2017 & 412.73 & 158.63 & 142.89 & $1,109.94$ & 158.64 \\
\hline PED visit rate - 2015/2017 & 415.38 & 160.59 & 143.57 & $1,131.52$ & 156.48 \\
\hline Material deprivation index & -0.01 & 0.03 & -0.11 & 0.09 & 0.04 \\
\hline Social deprivation index & 0.00 & 0.03 & -0.07 & 0.09 & 0.04 \\
\hline Healthcare facility & 0.43 & 0.21 & 0.02 & 1.00 & 0.32 \\
\hline Age 0-4 & 5.32 & 1.39 & 1.69 & 13.89 & 1.37 \\
\hline Age 5-9 & 5.63 & 1.52 & 0.76 & 10.57 & 1.71 \\
\hline Age 10-14 & 5.53 & 1.55 & 0.47 & 10.15 & 1.83 \\
\hline Age 15-17 & 3.44 & 0.88 & 0.33 & 6.60 & 1.05 \\
\hline Female & 19.09 & 4.58 & 3.41 & 34.72 & 5.61 \\
\hline Male & 20.82 & 4.89 & 3.14 & 36.49 & 5.81 \\
\hline CMA-Level Predictors & Mean & Std Dev & Minimum & Maximum & IQR \\
\hline Family physician & 1.15 & 0.26 & 0.69 & 2.06 & 0.35 \\
\hline Rate per children population & & & & & \\
\hline $\begin{array}{l}\text { Note: CMA: census metropolitan area; FSA: forward sortation area; PED: pediatric emergency } \\
\text { department; IQR: interquartile range; Std Dev: standard deviation }\end{array}$ & \\
\hline
\end{tabular}

\section{Multilevel Regression Models}

The results for the random effects from the multilevel regression models are presented in Table 3. In the variance component model (Model 1), the CMA and FSA variance estimates were both statistically significant $(16,266$ [ $p=0.0030]$ and 16,476 [ $<0.0001]$, respectively), with an intraclass correlation coefficient (ICC) of $49.68 \%$. In the adjusted model (Model 2), after accounting for differential distribution of age and sex across FSAs, the CMA and FSA variance estimates decreased by $4.67 \%$ and $6.87 \%$ but remained statistically significant $(15,506[p=0.0030]$ and 15,344 [p $<0.0001]$, respectively), with $50.25 \%$ of the overall variation in FSA-level PED visit rates attributable to differences across CMAs (i.e., inter- 
metropolitan variations) and the remaining $49.74 \%$ attributable to differences between FSAs (i.e., intrametropolitan variations).

Results for the fixed effects from the final multilevel model (Model 3) indicated that three out of the four contextual predictors (i.e., social deprivation, proximity to healthcare facilities, and supply of family physicians) had a statistically significant association with the FSA-level rate of PED visits; material deprivation was not statistically significant. Specifically, more socially deprived FSAs, FSAs with decreased proximity to healthcare facilities, and CMAs with a higher rate of family physicians per 1,000 children population had higher rates of PED visits; one SD increase in the social deprivation index (SD = 0.03 ) and in the rate of family physicians $(S D=0.26)$ as well as one SD decrease in the proximity to healthcare facilities (SD $=21$ ) were associated with an increase in the PED visit rates of $16.74,44.26$, and 68.10 per 1,000 children population, respectively (see Table 4). In terms of the effect of these predictors on the geographic variation, CMA- and FSA-level variances decreased by $31.41 \%$ (i.e., from 15,506 to 10,635 ) and by $18.61 \%$ (i.e., from 15,344 to 12,488 ), respectively (see Table 3 ).

Table 3

- Random effects and fit statistics

\begin{tabular}{|c|c|c|c|c|c|c|c|c|c|}
\hline Model & Estimate & Variance & SE & $\begin{array}{l}\mathrm{t}- \\
\text { value }\end{array}$ & p-value & ICC & $-2 \log$ & AIC & $\mathrm{BIC}$ \\
\hline \multirow[t]{2}{*}{$\begin{array}{l}\text { Model } \\
1\end{array}$} & $\begin{array}{l}\text { CMA- } \\
\text { level }\end{array}$ & 16,266 & $5,931.11$ & 2.74 & 0.003 & 49.68 & 6568.7 & 6572.7 & 6574.6 \\
\hline & $\begin{array}{l}\text { FSA- } \\
\text { level }\end{array}$ & 16,476 & $1,041.07$ & 15.83 & $<.0001$ & & & & \\
\hline \multirow[t]{2}{*}{$\begin{array}{l}\text { Model } \\
2\end{array}$} & $\begin{array}{l}\text { CMA- } \\
\text { level }\end{array}$ & 15,506 & $5,648.62$ & 2.75 & 0.003 & 50.26 & 6504.4 & 6508.4 & 6510.3 \\
\hline & $\begin{array}{l}\text { FSA- } \\
\text { level }\end{array}$ & 15,344 & 973.48 & 15.76 & $<.0001$ & & & & \\
\hline \multirow[t]{2}{*}{$\begin{array}{l}\text { Model } \\
3\end{array}$} & $\begin{array}{l}\text { CMA- } \\
\text { level }\end{array}$ & 10,635 & $4,053.18$ & 2.62 & 0.0043 & 45.99 & 6346.8 & 6350.8 & 6352.7 \\
\hline & $\begin{array}{l}\text { FSA- } \\
\text { level }\end{array}$ & 12,488 & 794.71 & 15.71 & $<.0001$ & & & & \\
\hline
\end{tabular}

Note: AIC: Akaike's Information Criterion; BIC: Bayesian Information Criterion; CMA: census metropolitan area; DF: degrees of freedom; FSA: forward sortation area; ICC: intraclass correlation coefficient; SE: standard error 
Table 4

- Fixed effects

\begin{tabular}{|c|c|c|c|c|c|c|c|}
\hline Model & Effect & Estimate & SE & $\begin{array}{l}\mathrm{t}- \\
\text { value }\end{array}$ & p-value & Lower & Upper \\
\hline $\begin{array}{l}\text { Model } \\
1\end{array}$ & Intercept & 467.17 & 30.57 & 15.28 & $<.0001$ & 402.88 & 531.46 \\
\hline \multirow{7}{*}{$\begin{array}{l}\text { Model } \\
2\end{array}$} & Intercept & 468.87 & 29.82 & 15.72 & $<.0001$ & 406.15 & 531.6 \\
\hline & \multicolumn{7}{|l|}{ Age 0-4 (REF) } \\
\hline & Age 5-9 & -28.80 & 17.26 & -1.67 & 0.0959 & -62.71 & 5.12 \\
\hline & Age $10-14$ & -53.87 & 15.83 & -3.40 & 0.0007 & -84.97 & -22.77 \\
\hline & Age 15-17 & -1.78 & 17.22 & -0.10 & 0.9175 & -35.62 & 32.05 \\
\hline & \multicolumn{7}{|l|}{ Male (REF) } \\
\hline & Female & 22.40 & 6.95 & 3.22 & 0.0014 & 8.74 & 36.06 \\
\hline \multirow{11}{*}{$\begin{array}{l}\text { Model } \\
3\end{array}$} & Intercept & 445.74 & 25.00 & 17.83 & $<.0001$ & 392.96 & 498.51 \\
\hline & \multicolumn{7}{|l|}{ Age 0-4 (REF) } \\
\hline & Age 5-9 & -1.88 & 16.11 & -0.12 & 0.9074 & -33.53 & 29.78 \\
\hline & Age 10-14 & -18.45 & 15.93 & -1.16 & 0.2471 & -49.74 & 12.84 \\
\hline & Age 15-17 & -12.40 & 16.71 & -0.74 & 0.4584 & -45.24 & 20.44 \\
\hline & \multicolumn{7}{|l|}{ Male (REF) } \\
\hline & Female & 4.54 & 6.62 & 0.69 & 0.4935 & -8.47 & 17.54 \\
\hline & $\begin{array}{l}\text { Material deprivation } \\
\text { index }\end{array}$ & -308.56 & 227.08 & -1.36 & 0.1748 & -754.70 & 137.57 \\
\hline & Social deprivation index & 562.82 & 271.97 & 2.07 & 0.0390 & 28.47 & 1097.17 \\
\hline & Healthcare facility & -324.41 & 32.95 & -9.85 & $<.0001$ & -389.14 & -259.68 \\
\hline & Family physician & 171.76 & 75.28 & 2.28 & 0.0354 & 13.13 & 330.39 \\
\hline
\end{tabular}

Note: $\mathrm{Cl}$ : confidence interval; REF: reference category; SE: standard error

Finally, Table 5 and Fig. 1 presents (1) crude rates of PED visits for each of the 19 CMAs, (2) estimated rates from the variance component model, (3) estimated rates from the adjusted model, and (4) estimated rates from the adjusted model with four contextual predictors. The results from the model with confounding and contextual predictors indicate that Thunder Bay, St. Catharines - Niagara, Belleville, and Brantford, Ontario had significantly higher rates of PED visits $(651.88,575.59,563.93$, and 553.65, respectively), while Windsor, Ottawa, and Kitchener - Cambridge - Waterloo, Ontario, had significantly 
lower rates of PED visits $(259.09,341.58$, and 358.68 , respectively) than the overall mean rate of PED visits of 445.74 per 1,000 children population. None of the three CMAs in Alberta had significantly different rate than the overall rate of PED visits. The results presented in Table 5 indicate that, across all models, the rates in Thunder Bay and St. Catharines - Niagara were significantly higher than the overall rate while the rates for Windsor and Kitchener - Cambridge - Waterloo were significantly lower than the overall rate.

Table 5

- Census metropolitan area-level rates of pediatric emergency department visits

\begin{tabular}{|lllll|}
\hline CMA & Crude Rate & Model 1 & Model 2 & Model 3 \\
\hline Windsor* & 237.19 & 248.28 & 267.15 & 259.09 \\
\hline Ottawa* $^{*}$ & 389.18 & 390.83 & 395.44 & 341.58 \\
\hline Kitchener - Cambridge - Waterlo** $^{*}$ & 303.65 & 310.27 & 315.36 & 358.68 \\
\hline Greater Sudbury & 395.17 & 401.24 & 399.92 & 369.47 \\
\hline Lethbridge & 450.66 & 453.45 & 443.39 & 374.35 \\
\hline Edmonton & 469.68 & 469.63 & 446.31 & 395.65 \\
\hline Calgary & 457.36 & 457.59 & 434.69 & 405.92 \\
\hline Toronto & 348.90 & 349.56 & 354.96 & 406.36 \\
\hline Barrie & 381.66 & 398.94 & 410.56 & 415.94 \\
\hline Guelph & 376.72 & 389.79 & 403.20 & 416.65 \\
\hline Oshawa & 369.61 & 375.79 & 389.54 & 438.93 \\
\hline Average & 469.37 & 467.17 & 468.87 & 445.74 \\
\hline London & 524.05 & 521.84 & 520.26 & 472.76 \\
\hline Hamilton & 474.56 & 474.32 & 479.48 & 476.33 \\
\hline Peterborough & 545.95 & 534.57 & 532.00 & 489.80 \\
\hline Kingston & 701.51 & 675.18 & 680.68 & 502.49 \\
\hline Brantford* & 560.55 & 550.05 & 561.07 & 553.65 \\
\hline Belleville* & 590.42 & 569.66 & 565.37 & 563.93 \\
\hline St. Catharines -Niagara* & 569.58 & 564.40 & 570.77 & 575.59 \\
\hline Thunder Bay* & 771.65 & 740.85 & 738.35 & 651.88 \\
\hline *p<0.05 & & & & \\
\hline
\end{tabular}

\section{Discussion}


The objective of this study was to assess the intra- and inter-metropolitan variation in PED visits in CMAs in Ontario and Alberta, Canada and to assess if contextual predictors related to material and social deprivation, proximity to healthcare facilities, and supply of family physicians can account for this variation. In total, there were 2,537,442 PED visits across 520 FSAs in CMAs in Alberta and Ontario. The overall crude FSA-level rate of PED visits was 415.38 per 1,000 children population. We found evidence of statistically significant and substantial intra- and inter-urban variation in the rates of PED visits. The interquartile range in FSA-level rates was 156,48 per 1,000 children population and, at the CMA level, the crude rate of PED visits was highest in Thunder Bay (771.65 per 1,000 children population) and lowest in Windsor (237.19 per 1,000 children population). In terms of the intra- and inter-metropolitan variation in PED visits, the FSA- and CMA-level variances were statistically significant across all models (before and after adjusting for age and sex and considering the contextual predictors). About $50 \%$ of the overall variance was due to differences between CMAs. The contextual predictors accounted for $31.41 \%$ and $18.61 \%$ of the CMA- and FSA-level variance, respectively; however, most of the original observed variation was not accounted for. Together, this indicates that there are significant inequalities in FSA-level rate of PED visits across CMAs and across FSAs that cannot be fully explained by age and sex distributions, nor by differences in material and social deprivation, proximity to healthcare facilities, or supply of family physicians. Furthermore, in the adjusted model including the contextual predictors, Thunder Bay, St. Catharines - Niagara, Belleville, and Brantford had significantly higher rates of PED visits than the overall mean rate of ED visits $(651.88,575.59,563.93$, and 553.65 per 1,000 children population, respectively), whereas Windsor, Ottawa, and Kitchener - Cambridge - Waterloo, had significantly lower rates of PED visits $(259.09,341.58$, and 358.68 per 1,000 children population, respectively). The three CMAs in Alberta were not significantly different from the overall mean rate reported in the adjusted model with contextual predictors.

Our findings indicate that across the 19 CMAs included in this study, Thunder Bay - a CMA in northern Ontario - had the highest average rate of PED visits across all models. This finding aligns with previous research which indicates residents of northern Ontario have poorer geographic access to primary healthcare, hospitals, and worse health status and outcomes [12, 27]. This is not just limited to adults, as children and youth living in northern Ontario had higher rates of hospitalization and mortality than the provincial rate [28]. Windsor, on the other hand, had the lowest average rate of PED visits across all models.

Geographic inequalities and intra-urban variation have been identified in previous studies in the provinces of Alberta and Ontario. In Calgary and Edmonton, Alberta, Serrano-Lomelin et al. found geographic inequalities and intra-urban variations in use of acute respiratory health services (hospitalizations and ED visits) during early childhood that could not be completely explained by area-level material and social deprivation, suggesting that other unmeasured contextual factors also played a role in influencing the use of these services [7]. They also found that small conglomerate areas across the city of Calgary had greater demand for acute pediatric respiratory health services, whereas in Edmonton, the demand for these services followed a regional-cluster spatial distribution [7]. Sheriff et al. found that the highest number of hot spots for pediatric asthma-related ED visit and re-visit rates in Ottawa, Ontario were within areas that 
were associated with neighborhood residential instability, material deprivation, dependency, and ethnic concentration [6].

This study addresses inequalities in overall ED utilization among children living in CMAs in Ontario and Alberta. We found that more socially, but not materially, deprived FSAs had increased rates of PED visits. Material and social deprivation have previously been found to be associated with increases in overall [29] and low-acuity [30] ED visits among the general population and with recurrent ED visits among the pediatric population [31]. Belon et al. found that social and material deprivation were significantly associated with episodes of care for pediatric respiratory diseases in Alberta; however, contrary to our study, there was a more consistent gradient of increased rates of ED visits for all respiratory diseases with material deprivation [15]. Children are often accompanied by parents or caregivers to the ED, and parents' decision to seek care in EDs are complex and often extend beyond measures of socioeconomic status. Driving factors for parents bringing their child to the ED include feelings of anxiety, urgency, need for immediate care and reassurance, perceptions that the ED was the best place to receive care, and the convenience and access of EDs (i.e., not needing appointment and around-the-clock care). These feelings and perceptions may be exacerbated in single-parent families or among those who experience greater social deprivation, resulting in higher rates of ED visits [32, 33].

Closer proximity to healthcare facilities was associated with reduced rates of PED visits in our study, which is consistent with previous research. Results from a study in the United States found that children living closer to their primary care physician had lower ED use, while those living closer to an ED had higher ED use [14]. Although we did not assess proximity to hospitals separately, research has indicated that proximity to an ED results in higher use. In British Columbia, geographic proximity was one of the top reasons for parents' bringing their child to the ED for non-emergent complaints [34]. Similarly, Shechter et al. found that living closer to the ED compared to the clinic was a significant predictor of ED utilization among children in the United States [35]. Thus, separate measures of proximity to specific healthcare facilities (e.g., hospitals, primary healthcare clinics) should be considered in future studies assessing geographic inequalities in PED visits.

Interestingly, we found that CMAs with greater supply of family physicians also had higher rates of ED visits. While having greater numbers of family physicians would seemingly reduce rates of ED utilization, our results may stem from the unequal distribution of family physicians in an area, as opposed to absolute supply $[9,13]$. Furthermore, the accessibility of family physicians and primary healthcare services (e.g., hours, location) may also contribute to ED visits. Children in the United Kingdom registered in practices that were easily accessible were $9 \%$ less likely to visit the ED [36]. Given that the contextual factors related to social and material deprivation, proximity to healthcare facilities, and supply of family physicians did not account for all the variation in PED visits, it is likely that other social and environmental factors at the neighbourhood-level, (e.g., safety, air pollution, and features of the built environment), may also affect the utilization of the ED by children.

\section{Strengths And Limitations}


This study is not without limitations. First, FSAs were used to assess inter-metropolitan variation within CMAs because these were the smallest geographic units available; however, FSAs are known to have irregular boundaries and vary in size. Although we believe that FSAs are sufficient to assess overall intrametropolitan variation, future research is warranted using smaller units of geography as using such units could have generated different results. Secondly, 19 CMAs from Alberta and Ontario were used because only these two provinces are mandated to submit ED data to $\mathrm{CIHI}$. Although studies tend to focus on only a single province, city, or hospital, by assessing both Alberta and Ontario, we provided a better understanding of across CMA variation in PED visits in Canada. For this study, we were also able to link the ED data with contextual factors derived from the census data. Lastly, the health administrative data used in this study poses limitations related to the information included as these data do not capture any exposure related details that may be used to assess variation in PED visits.

\section{Conclusions}

In conclusion, there are geographic inequalities in the rates of PED visits across FSAs in Canada's large urban centers. As some urban areas have higher rates of PED visits, there is a need to further explore the role of contextual factors, as they are important in addressing health inequalities, particularly in urban settings.

\section{Abbreviations}

CMA - census metropolitan area

ED - emergency department

FSA - forward sortation area

PED - pediatric emergency department

\section{Declarations}

Ethics approval and consent to participate - Ethical approval was not required as this study used anonymous and confidential secondary data. Consent from respondents was obtained at the time of data collection.

Consent for publication - Not applicable.

Availability of data and materials - Data is available only through a data sharing agreement between Health Canada and the Canadian Institute for Health Information and the authors are not permitted to share the data.

Competing interests - No competing interests to declare. 
Funding - This research was supported by funding from the Canadian Institutes of Health Research (CIHR; Project Grant ID: 436432) The funder had no role in the study design; analysis or interpretation of data; writing of the manuscript; or in the decision to submit the study for publication.

Authors' contributions - All authors contributed to the study design. Analyses were performed by PW. The first draft of the manuscript was written by PW, TL, and AM. All authors contributed to interpretation and critical revision of the manuscript. All authors read and approved the final manuscript.

Acknowledgements - Statistics Canada/CMHC proximity data, indexed to DMTI postal codes, were accessed via the Canadian Urban Environmental Health Research Consortium (CANUE) data portal (canuedata.ca).

\section{References}

1. Canadian Institute for Health Information. NACRS Emergency Department (ED) Visits: Volumes and Median Length of Stay by Triage Level, Visit Disposition, and Main Problem. Ottawa, ON: ClHI; 2020.

2. Moylan A, Maconochie I. Demand, overcrowding and the pediatric emergency department. CMAJ. 2019;191(23):E625-E6. doi:10.1503/cmaj.190610

3. Doan Q, Wong H, Meckler G, Johnson D, Stang A, Dixon A, et al. The impact of pediatric emergency department crowding on patient and health care system outcomes: a multicentre cohort study. CMAJ. 2019;191(23):E627-E35. doi:10.1503/cmaj.181426

4. Doan Q, Genuis ED, Yu A. Trends in use in a Canadian pediatric emergency department. CJEM. 2014;16(5):405-10. doi:10.2310/8000.2013.131280

5. Statistics Canada. Canada's population estimates: Subprovincial areas, July 1, 2020 [Internet]. 2021 [Available from: https://www150.statcan.gc.ca/n1/en/daily-quotidien/210114/dq210114a-eng.pdf? st=b-fH7rky.

6. Sheriff F, Agarwal A, Thipse M, Radhakrishnan D. Hot spots for pediatric asthma emergency department visits in Ottawa, Canada. J Asthma. 2021. doi:10.1080/02770903.2021.1887891

7. Serrano-Lomelin J, Nielsen CC, Hicks A, Crawford S, Bakal JA, Ospina MB. Geographic inequalities of respiratory health services utilization during childhood in Edmonton and Calgary, Canada: A tale of two cities. Int J Environ Res Public Health. 2020;17(23):1-17. doi:10.3390/ijerph17238973

8. Lougheed MD, Garvey N, Chapman KR, Cicutto L, Dales R, Day AG, et al. The Ontario Asthma Regional Variation Study: emergency department visit rates and the relation to hospitalization rates. Chest. 2006;129(4):909-17. doi:10.1378/chest.129.4.909

9. Gilliland JA, Shah TI, Clark A, Sibbald S, Seabrook JA. A geospatial approach to understanding inequalities in accessibility to primary care among vulnerable populations. PLoS One. 2019;14(1):e0210113. doi:10.1371/journal.pone.0210113

10. Green M, Gozdyra P, Frymire E, Glazier R. Geographic Variation in the Supply and Distribution of Comprehensive Primary Care Physicians in Ontario, 2014/15. Toronto ON; 2017. 
11. Bissonnette L, Wilson K, Bell S, Shah TI. Neighbourhoods and potential access to health care: the role of spatial and aspatial factors. Health Place. 2012;18(4):841-53.

doi:10.1016/j.healthplace.2012.03.007

12. Ge E, Su M, Zhao R, Huang Z, Shan Y, Wei X. Geographical disparities in access to hospital care in Ontario, Canada: a spatial coverage modelling approach. BMJ Open. 2021;11(1):e041474. doi:10.1136/bmjopen-2020-041474

13. Guttmann A, Shipman SA, Lam K, Goodman DC, Stukel TA. Primary care physician supply and children's health care use, access, and outcomes: findings from Canada. Pediatrics. 2010;125(6):1119-26. doi:10.1542/peds.2009-2821

14. Ludwick A, Fu R, Warden C, Lowe RA. Distances to emergency department and to primary care provider's office affect emergency department use in children. Acad Emerg Med. 2009;16(5):411-7. doi:10.1111/j.1553-2712.2009.00395.x

15. Belon AP, Serrano-Lomelin J, Nykiforuk CIJ, Hicks A, Crawford S, Bakal J, et al. Health gradients in emergency visits and hospitalisations for paediatric respiratory diseases: A population-based retrospective cohort study. Paediatr Perinat Epidemiol. 2020;34(2):150-60. doi:10.1111/ppe.12639

16. Canadian Institute for Health Information. Data Quality Documentation, National Ambulatory Care Reporting System - Current-Year Information, 2019-2020. [Internet]. Ottawa, ON: CIHI; 2020 [Available from: https://www.cihi.ca/sites/default/files/document/nacrs-data-quality-current-yearinformation-2019-2020-en.pdf.

17. Statistics Canada. Population and Dwelling Count Highlight Tables, 2016 Census. 2018 [Available from: https://www12.statcan.gc.ca/census-recensement/2016/dp-pd/hlt-fst/pd-pl/Table.cfm? Lang=Eng\& $\mathrm{T}=101 \& \mathrm{~S}=50 \& \mathrm{O}=\mathrm{A}$.

18. Canadian Institute for Health Information. NACRS Abstracting Manual, 2018-2019. Ottawa, ON.; 2018.

19. Statistics Canada. Dictionary, Census of Population, 2016. Census metropolitan area (CMA) and census agglomeration (CA) [Internet]. 2016 [Available from: https://www12.statcan.gc.ca/censusrecensement/2016/ref/dict/geo009-eng.cfm.

20. Government of Canada. Forward Sortation Area-Definition [Internet]. 2015 [Available from: https://www.ic.gc.ca/eic/site/bsf-osb.nsf/eng/br03396.html.

21. Statistics Canada. Postal Code Conversion File Plus (PCCF+) Version 7C, Reference Guide.. 2019.

22. Pampalon R, Hamel D, Gamache P, Philibert MD, Raymond G, Simpson A. Un indice régional de défavorisation matérielle et sociale pour la santé publique au Québec et au Canada. Canadian Journal of Public Health. 2012;103(S2):S17-S22. doi:10.1007/bf03403824

23. CanMap Postal Code Suite v2015.3. Markam: DMTI Spatial Inc.; 2015.

24. Statistics Canada Canadian Mortgage and Housing Corporation. Proximity Measures Database Early release, April 17, 2020. 2020.

25. CanMap Postal Code Suite. Markham ON: DMTI Spatial Inc.; Various years. 
26. Canadian Medical Association. Number of physicians by census metropolitan area or census agglomeration Canada, 20172017 [Available from: https://www.cma.ca/sites/default/files/pdf/Physician\%20Data/13cma_ca.pdf.

27. Health Quality Ontario. Health in the North: A report on geography and the health of people in Ontario's two northern regions [Internet]. Toronto, ON: Queen's Printer for Ontario; 2017 [Available from: http://www.hqontario.ca/portals/0/Documents/system-performance/health-in-the-north-en.pdf.

28. Ward MS, Sahai VS, Tilleczek KC, Fearn JL, Barnett RC, Zmijowskyj T. Child and Adolescent Health in Northern Ontario. Canadian Journal of Public Health. 2005;96(4):287-90. doi:10.1007/bf03405166

29. Tozer AP, Belanger $P$, Moore $K$, Caudle J. Socioeconomic status of emergency department users in Ontario, 2003 to 2009. CJEM. 2014;16(3):220-5. doi:10.2310/8000.2013.131048

30. Vanstone NA, Belanger P, Moore K, Caudle JM. Socioeconomic composition of low-acuity emergency department users in Ontario. Can Fam Physician. 2014;60(4):355-62.

31. Seguin J, Osmanlliu E, Zhang X, Clavel V, Eisman H, Rodrigues R, et al. Frequent users of the pediatric emergency department. CJEM. 2018;20(3):401-8. doi:10.1017/cem.2017.15

32. Costet Wong A, Claudet I, Sorum P, Mullet E. Why Do Parents Bring Their Children to the Emergency Department? A Systematic Inventory of Motives. Int J Family Med. 2015;2015:978412. doi:10.1155/2015/978412

33. Butun A, Linden M, Lynn F, McGaughey J. Exploring parents' reasons for attending the emergency department for children with minor illnesses: a mixed methods systematic review. Emerg Med J. 2019;36(1):39-46. doi:10.1136/emermed-2017-207118

34. Smith V, Mustafa M, Grafstein E, Doan Q. Factors Influencing the Decision to Attend a Pediatric Emergency Department for Nonemergent Complaints. Pediatr Emerg Care. 2015;31(9):640-4. doi:10.1097/PEC.0000000000000392

35. Shechter J, Roy A, Naureckas S, Estabrook C, Mohanty N. Variables Associated with Emergency Department Utilization by Pediatric Patients with Asthma in a Federally Qualified Health Center. J Community Health. 2019;44(5):948-53. doi:10.1007/s10900-019-00653-6

36. Cecil E, Bottle A, Cowling TE, Majeed A, Wolfe I, Saxena S. Primary care access, emergency department visits, and unplanned short hospitalizations in the UK. Pediatrics. 2016;137(2). doi:10.1542/peds.2015-1492

\section{Figures}




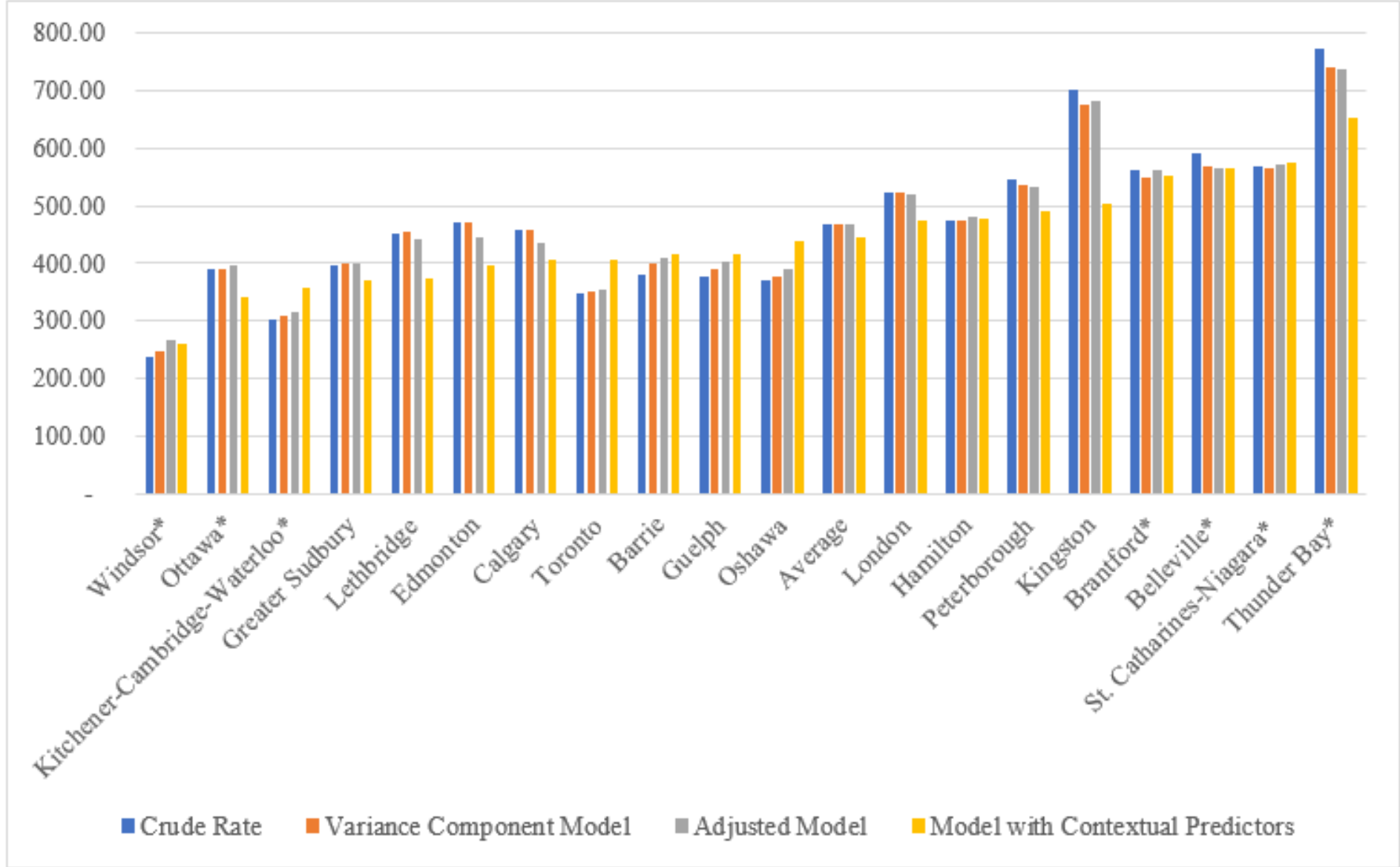

Figure 1

Rates of pediatric emergency department visits across census metropolitan areas 